\title{
Homophobia: A Psychodynamic Analysis
}

\author{
Jesús Dueñas Becerra* and Mariela Castro Espín \\ Honorary Member, Scuola Romana Rorschach, Italy \\ *Corresponding author: Jesús Dueñas Becerra, Honorary Member, Scuola Romana Rorschach, Italy \\ To Cite This Article: Jesús Dueñas Becerra. Homophobia: A Psychodynamic Analysis. Am J Biomed Sci \& Res. 2019 - 4(1). AJBSR.MS.ID.000751. \\ DOI: $10.34297 / A J B S R .2019 .04 .000751$
}

Received: July 02, 2019 | Published: July 16, 2019

\section{Opinion}

The World Day to Combat Homophobia and Transphobia is commemorated, in the Cuban archipelago and beyond our island geographical borders, since 1973; date in which homosexuality -as a no so graphic entity- was eliminated forever from the International Classification of Mental Illnesses. To evoke this historical event, I make this article available to the readers of this periodical publication.

It is not possible, in any way, to explain what homophobia is without first conceptualizing the words homosexuality and phobia. The specialized literature defines homosexuality as sexual preference or attraction for people of the same sex, while phobia describes it as intense and persistent fear towards a specific object, situation or activity.

Homophobia, as a superficial motivation of the subject's behaviour, is the fear of homosexuality, but from the depths of human subjectivity it is nothing other than the fear of the homoerotic impulses that emerge from the instinctive component of the Freudian unconscious.

Homophobia manifests itself through intolerant attitudes towards those individuals with homosexual behaviour; attitudes ranging from contempt to physical or verbal aggression and are an expression of an unconscious mechanism that Sigmund Freud, the Father of Psychoanalysis, called projection (attribute to people, situations or things hostile feelings that seize the subject).

For the person with homophobia, the subject with homoerotic sexual orientation is a «plague» or «incurable patient», whose proximity can «infect the supposedly healthy», and when, for one reason or another, circumstances require him to interact with that other person «different» is not only decompensated from the psychic point of view, but also blocks emotional intelligence, understood as the difficult art of putting our feelings and emotions in order to optimize the relationship with others.

A not insignificant percentage of people with homophobia present an intrapsychic conflict, which is revealed by means of a struggle between the id (unconscious) and the ego (consciousness) or between the ego and the superego (ethical-moral censor that regulates the psychosocial behaviour of the subject, and that responds to the interests of family, religion, school, culture, patriarchal society and sexist).

In other words, they are people who repress this variant of human sexual behaviour; a tendency that crouches in the instinctive component of the Freudian unconscious, and in response to repression is expressed through failed acts or erotic dreams with subjects of the same sex. Or they are individuals, who after a «pitched battle» that wears them physically, psychically and spiritually have internalized their homosexuality, but due to socio-family or other pressures they refuse to incorporate this homoerotic orientation to their sexual behaviour, and by extension, to his personality; resistance that leads the subject to a new confrontation with himself, which triggers a psychological conflict of neurotic level.

However, there are individuals who do not present these unconscious conflicts cannot get rid of homophobia, because they suspect or have discovered homosexuality in their children, parents, brothers ..., and to «cover» the alleged faults of their loved ones are dedicated to persecute, stigmatize or destroy psychologically, socially, morally and spiritually people who in their intimate relationship prefer the other of their own sex. I do not think it necessary to insist on the particular, because - according to an illustrious American intellectual- «there are truths so evident, that trying to prove them is an insult to reason».

Finally, I would like to highlight the intelligent attitude adopted by a healthy person of body, mind and spirit toward men and women with homosexual behaviour: The individual without homophobia perceives the other as «different» as a person who is worth not because of his sexual orientation, but because of what he is: an unfinished and endless being, imperfect but perfectible, that integrates into a living unit each and every one of its dimensions bio-psycho socio culturales and spiritual ..., which make it a unique, special and unrepeatable person, who deserves love and respect for his inviolable human dignity.

Once the sovereign of creation interiorizes and incorporates into his style of confrontation that eminently ethical-humanist attitude, there is no doubt that we will be living in that better world ... that is possible. 